\title{
Examining welfare receipt and mental disorders after a decade of reform and prosperity: analysis of the 2007 National Survey of Mental Health and Wellbeing
}

\author{
Peter Butterworth, Philip M. Burgess, Harvey Whiteford
}

\begin{abstract}
Objectives: To estimate the prevalence of mental disorders among Australian income support recipients in 2007, and to evaluate whether this has changed over the past 10 years. Methods: Analysis of data from the 2007 National Survey of Mental Health and Wellbeing (NSMHWB), a nationally representative survey of 8841 community-dwelling residents. The data were used to estimate and classify those working-age survey respondents who were income support recipients into categories reflecting major payment types, and to estimate the 12-month prevalence of affective, anxiety and substance use disorders. Data from the 1997 NSMHWB were also used for comparison.

Results: The 12-month prevalence of mental disorders among working-age recipients was $34 \%$ compared to $20 \%$ for non-recipients. Rates of mental disorders were elevated among all categories of income support recipients, including the unemployed, lone parents, partnered parents, and those classified as receiving disability payments. There were limited differences between the results from the two surveys. A marked increase in the prevalence of mental disorders in partnered parent recipients (from $21 \%$ in 1997 to $39 \%$ in 2007) seemed due to methodological differences in the estimation of income support categories and likely reflected greater accuracy of the 2007 estimate.

Conclusions: Income support recipients are much more likely to experience mental disorders than those not receiving payments and there has been little change in the strength of the association between income support receipt and mental disorders over the past decade. Mental disorders represent a substantial barrier to work, community engagement and social participation. A greater focus on mental health in the design and delivery of social policy and services may be an appropriate strategy to promote more positive outcomes in areas such as welfare, employment and social inclusion.
\end{abstract}

Key words: mental disorders, epidemiology, income support.

\section{Australian and New Zealand Journal of Psychiatry 2011; 45:54-62}

\footnotetext{
Peter Butterworth, NHMRC Research Fellow (Correspondence)

Centre for Mental Health Research, Building 63, Australian National University, Canberra, ACT, Australia. Email: Peter.Butterworth@anu. edu.au

Philip M. Burgess, Professor; Harvey Whiteford, Professor

School of Population Health, University of Queensland, Queensland Centre for Mental Health Research, Queensland, Australia

Received 9 June 2010; accepted 1 September 2010.
}

There is growing recognition of the need to consider mental disorders in the design and delivery of mainstream public policy rather than mental health being exclusively a concern of specialist medical and segregated disability policies and services [1,2]. For example, the Council of Australian Government (COAG) National Action Plan on Mental Health, endorsed by the Federal and all State and 
Territory governments, emphasizes the role of services outside the health sector, including employment and education, to promote recovery and assist people with mental disorders to participate fully in community life [3]. The common mental disorders, defined here as anxiety, affective and substance use disorders, are prevalent in the community and are associated with significant disability and impairment [4,5]. As such, mental disorders can have a significant impact on an individual's capacity to work and earn an income [6-8]. Therefore, mental health has direct relevance to mainstream Australian employment and income support policy.

Data from the 1997 National Survey of Mental Health and Wellbeing (NSMHWB), the first nationally representative survey of mental disorders in Australia, were analysed in a series of papers which demonstrated the elevated prevalence of common mental disorders (affective, anxiety and substance-use disorders) amongst working-age income support recipients in Australia [9-11]. These analyses considered different categories of income support recipients and found that rates of common mental disorders were as high or higher among lone parent and unemployed payment recipients as they were among those classified as receiving disability payments, and significantly elevated in all these groups compared with nonrecipients. This body of research provided an evidence base for policy development in welfare and employment services, including the identification of policies and service delivery strategies to assist income support recipients with common mental disorders [12], and insight into the wider societal costs of mental illness [13].

In the decade following the first survey there was much change in the income support and mental health service systems, as well as in the broader societal context. The mental health service changes have been described previously in this journal $[14,15]$ and included the expansion of subsidized services for allied health professionals and better support for the role of general practice in mental health service provision. At the same time, Australia along with other western countries undertook considerable reform of the welfare system [16-18]. The reforms placed a greater emphasis on ensuring individuals receiving welfare payments were active, that is, undertaking work, job search or work-like activity as a condition of payment [19]. Mutual obligations and workfor-the-dole became the Australian focus of welfare reform [20,21]. Participation requirements were extended to those receiving parenting payments once their youngest child reached school age, and similar participation requirements were introduced for the disability support pension, along with a tightening of the eligibility requirements [22]. It was also a period of economic prosperity. Between 1997 and 2007 real GDP increased from
AU $\$ 38,200$ to $\$ 49,000$ per person per year, the unemployment rate declined from $8.3 \%$ to $4.5 \%$, the labour force participation rate rose from $31.1 \%$ to $48.4 \%$ for women and from $60.5 \%$ to $67.9 \%$ for men, and the number of people receiving unemployment payments fell from 798,000 to 486,500 , corresponding to a decline from $8.7 \%$ to $4.5 \%$ of the total labour force [23].

The availability of data from the second NSMHWB conducted in 2007 provides an opportunity to evaluate whether these policy and contextual changes have altered the circumstances of income support recipients in Australia. While early findings showed that the overall prevalence of mental disorders in the population has remained relatively stable [24], there may have been changes in the profile of mental disorders among those receiving income support payments. Increased employment opportunities and access to more appropriate mental health and welfare assistance may have improved the outcomes of those income support recipients with mental disorders. Alternatively, it may have been those income support recipients who were most disadvantaged, such as those with mental disorders, who failed to benefit from the prosperous times and enhanced services. The aim of the current paper, therefore, is to use data from the 2007 NSMHWB to estimate the prevalence and profile of mental disorders among those receiving income support payments. The paper also compares the 1997 and 2007 prevalence estimates. There are, however, a number of methodological differences between the 1997 and 2007 surveys, including use of different versions of the diagnostic instrument, which makes direct comparison of results across surveys problematic [24]. Further, in both the 1997 and 2007 analyses, the different categories of income support recipients were approximated, based on demographic characteristics. The 2007 survey included different but more extensive socioeconomic measures than the 1997 survey. Therefore, we anticipate that classification of respondents may differ between surveys but that the 2007 classification may more accurately reflect actual payment.

\section{Method}

\section{Sample}

This analysis used the confidentialized unit record file (CURF) of the 2007 NSMHWB [25]. The survey was conducted by trained interviewers from the Australian Bureau of Statistics. The NSMHWB employed a stratified, multistage area probability sample of private dwellings from across Australia, and selected one household member aged between 16 and 85 years from each household for interview. Overall, 8841 respondents from 14805 sampled households agreed to complete the interview; a response rate of $60 \%$. For further details of the survey are available elsewhere [24,25]. The current analysis also 
draws on data from the 1997 National Survey. Details of this survey $[26,27]$ and description of the previous analysis of income support recipients using this dataset [9] has been previously reported.

\section{Measures}

The primary diagnostic component of the 2007 survey was based on the World Mental Health Composite International Diagnostic Interview (WMH-CIDI 3.0 [28]) which assessed lifetime prevalence. The interview also assessed mental health symptoms in the previous 12 months and 30 days, which enabled estimation of 12-month and 30-day prevalence. For this analysis, we focus on whether respondents met ICD-10 criteria [29] for any affective disorder, any anxiety disorder and any substance use disorder in the past 12 months. Interviews were conducted via computer-assisted personal interview procedure.

The survey also collected data on respondents' demographic and social circumstances, including age, sex, sources of household and personal income, equivalized household income, marital and partner status, household composition and relationships within the household, labour-force status, and hours worked.

The 1997 survey based estimates of diagnosis on the CIDI 2.1, which initially evaluated 12 -month rather than lifetime prevalence. The survey achieved a $78 \%$ response rate. As described earlier, there were also other differences between the two CIDI instruments and the range of socio-demographic variables included in the two surveys.

\section{Analysis}

This analysis focused on respondents between 18 years and age pension age (which in 2007 was 65 years for males and 63 years for females). Similar to the 1997 analysis, data on specific income support payments received was not available on the dataset for privacy reasons. Therefore, based on their demographic and social characteristics, we classified respondents who reported receiving a government pension or payment into one of five subgroups representing major types of income support payments. These payment types were: unemployed; students; partnered parents; lone parents; and those not in the labour force (NILF) (primarily reflecting disability support pension and other payments that do not require active job search). The variables available in the 2007 dataset for this classification differed from those available in 1997 and included more extensive socioeconomic data at both the individual and household level. The measures used in algorithms to estimate payment type were sex, relationship/marital status, household income, sources of income (individual and household), main source of personal income, family composition, labour-force status, study status, hours worked, relationship in household, and presence of children. For example, lone parent income support recipients were men and women who identified themselves as lone parents, were under age pension age, had children aged less than 17 years living in their household, were not in a registered marriage or de facto relationship, were not in fulltime education, and reported that their personal and household income included government pensions or allowances. Further details of the derivation of income support categories is available on request from the first author.

The analyses initially contrasted estimates of the population of income support recipients derived from the survey with administrative data [17, $30-32]$ to evaluate the validity of the classification. The multiple sources of administrative data were used to provide coverage of all relevant sub-populations, and in some instances estimates of the population profile of income support recipients from one source (e.g. age, sex) were applied to overall population figures from another. Second, we report the 12-month prevalence of affective, anxiety and substanceuse disorders among working-age income support recipients and nonrecipients. The association between income support receipt and mental health was assessed using logistic regression models and included age and sex as covariates. The data were weighted to population benchmarks, and jack-knife replicate weights provided by the ABS were used to derive standard errors and confidence intervals. Within the different client groups we also considered the severity of disorder, that is the impairment for those with mental disorders categorized as mild, moderate or severe on the basis of diagnosis, role impairment and overall functional impairment [25]. Finally, we contrast the 1997 and 2007 results and investigate whether observed differences are more likely to reflect changes in the survey methodology and/or measurement rather than real changes in prevalence in the populations. For the comparative analysis, the two datasets were combined, and estimates evaluated using the relevant jack-knife replicate weights [33,34]. Age and sex were included as covariates in these analyses. After initially evaluating the main effect of study, a model incorporating interaction terms between each payment type and study were tested. All statistical analyses were conducted using STATA 10.0.

\section{Results}

Administration data from the Commonwealth Department of Families, Housing, Community Services and Indigenous Affairs shows that, in June $2007,16.9 \%$ of the working age Australian population (16 to 64 years) were receiving either full or part rate income support payments [17]. Research conducted by the Parliamentary Library reports a figure of $17.4 \%$ for the same period [32]. Using the 2007 NSMHWB data, we estimated that $17.3 \%$ (95\% confidence interval: $16.1 \%$ to $18.5 \%$ ) of the Australian population aged between 18 and age pension age were receiving income support payments.

Table 1 contrasts the administrative data (with data drawn from Harmer [17], Department of Families, Housing, Community Services and Indigenous Affairs [30] and Daniels [32]) and the 2007 NSMHWB estimates for the five income support payment groups. It is evident that the estimates derived from the 2007 NSMHWB closely approximate the administrative data. The greatest disparity was evident for the partnered parent group, which overestimated the population by $15 \%$, though the actual population size was within the $95 \%$ confidence interval of the estimate.

Income support recipients reported an elevated prevalence of mental disorders (12-month prevalence of affective, anxiety and substanceuse disorders) compared to non-recipients (see Table 2). This was the case for income support recipients overall (bottom row) and for almost all of the different payment groups identified. The only exceptions were anxiety disorders among students and substance use disorders among partnered parents. The low prevalence of 12-month substance use disorders and the small sample of partnered parent recipients precluded the calculation of reliable estimates. A series of logistic regression models confirmed that those receiving income support payments were more likely to have experienced a CIDI-diagnosed affective 


\begin{tabular}{|c|c|c|c|}
\hline \multicolumn{4}{|c|}{ Table 1. 2007 welfare population and estimates from the 2007 NSMHWB } \\
\hline & \multirow{2}{*}{$\begin{array}{c}\text { Administrative } \\
\text { data }\end{array}$} & \multicolumn{2}{|c|}{2007 NSMHWB } \\
\hline & & Estimates & $95 \% \mathrm{Cl}$ \\
\hline Unemployed & 469880 & 471468 & $394455-548481$ \\
\hline Students & 204135 & 205342 & $139237-271448$ \\
\hline Partnered parents & 144427 & 156185 & $115238-219132$ \\
\hline Lone parents & 395495 & 395808 & $313997-477619$ \\
\hline Not in the labour force & 989882 & 982305 & $878630-1085981$ \\
\hline
\end{tabular}

(odds ratios $(\mathrm{OR})=2.74,95 \% \mathrm{CI} 2.13-3.54)$, anxiety $(\mathrm{OR}=2.11$, $1.68-2.66)$ or substance use disorder $(\mathrm{OR}=1.48,1.07-2.04)$ than non-recipients. Similarly, income support recipients were more likely to report any mental disorder than non-recipients $(\mathrm{OR}=2.11$, 1.74-2.55). Results for the individual income support client groups are presented in Table 3.

It was estimated that 761200 income support recipients in Australian met criteria for a 12 -month mental disorder. Of these, 421800 or $55 \%$ were receiving a payment other than disability support pension.

Figure 1 presents the level of severity of those survey respondents with mental disorders separately for non-recipients and the five client groups. The unemployed and NILF/disability payment recipients were more likely to report severe impairment from their disorder(s) than non-recipients $(\mathrm{OR}=2.66,1.33-5.33$ and $\mathrm{OR}=2.86,1.87-4.39$ respectively). The prevalence of severe impairment in the other income support client groups did not differ from that evident among non-recipients. When analysis considered moderate and severe impairment, the lone parent client group also showed a tendency to be more impaired than non-recipients $(\mathrm{OR}=2.34,0.92-6.0)$.

The next set of analyses contrast the 2007 and 1997 results, considering 12-month prevalence of any mental disorder. Overall, the prevalence of mental disorders among income support recipients was somewhat greater in 2007 than 1997 (34.3\% versus 30.8\%), though this difference was not statistically significant $(\mathrm{OR}=1.17,0.94-46)$. The prevalence of mental disorders across the different payment types from the two surveys is presented in Figure 2. An initial logistic regression model, with age and sex as covariates, again found no significant effect of study ( $\mathrm{OR}=1.12,95 \% \mathrm{CI} 0.91-1.38$ ). Consideration of the regression terms representing the interaction between each payment type and study confirms the pattern of results evident in Figure 2, showing that the prevalence of mental disorders among partnered parent recipients was significantly greater in 2007 than 1997 (OR for this difference $=2.64,1.14-5.94)$. No other interaction term was significant, suggesting the prevalence of mental disorders among the other types of income support recipients did not reliably differ between the two surveys. Nonetheless, it is interesting to note that for lone parent recipients the prevalence estimates dropped from $45 \%$ to $38 \%$ while the prevalence estimate for the NILF/disability group increased from $30 \%$ to $35 \%$.

To investigate whether the differences evident between surveys were due to differences in the way that the payment groups were constructed, we recalculated the 2007 estimates using an approach more similar to that used with the 1997 data (see third category in Figure 2). This involved consideration of a much larger group of partnered parents who received some form of government payment. For the other categories of income support recipients we considered the subgroups of individuals who received payments as their main source of income rather than those who reported any level of government pension or payment. For some categories of income support recipients (Unemployed,

Table 2. 12-month prevalence of mental disorders amongst income support recipients (overall and main payment categories) and non-recipients, reporting percent and 95\% confidence intervals

\begin{tabular}{|c|c|c|c|c|}
\hline & \multicolumn{4}{|c|}{ ICD-10 CIDI diagnosis of 12 month prevalence } \\
\hline & $\begin{array}{l}\text { Affective disorders } \\
\text { (\% \& Cl) }\end{array}$ & $\begin{array}{l}\text { Anxiety disorders } \\
(\% \& \mathrm{Cl})\end{array}$ & $\begin{array}{c}\text { Substance use } \\
\text { disorders (\% \& Cl) }\end{array}$ & $\begin{array}{c}\text { Any mental } \\
\text { disorder }(\% \& \mathrm{Cl})\end{array}$ \\
\hline \multirow[t]{2}{*}{ No income support } & 5.7 & 14.2 & 5.3 & 19.7 \\
\hline & $4.89-6.46$ & $12.79-15.52$ & $4.46-6.12$ & $18.13-21.19$ \\
\hline \multirow{2}{*}{ Unemployed } & 15.2 & 21.0 & 10.5 & 31.2 \\
\hline & 8.18-22.3 & $13.39-28.64$ & $4.55-16.4$ & $22.0-40.46$ \\
\hline \multirow[t]{2}{*}{ Students } & 9.3 & 13.7 & 13.8 & 29.5 \\
\hline & $1.04-17.65$ & $5.48-21.96$ & $3.73-23.96$ & $16.53-42.43$ \\
\hline \multirow[t]{2}{*}{ Partnered parents } & 17.9 & 26.4 & - & 39.1 \\
\hline & $3.51-32.36$ & $12.9-39.92$ & & $20.57-57.59$ \\
\hline \multirow[t]{2}{*}{ Lone parents } & 11.3 & 28.8 & 9.4 & 37.6 \\
\hline & $7.2-15.38$ & $17.62-39.92$ & $2.6-16.2$ & $26.0-49.14$ \\
\hline \multirow{2}{*}{ Not in the labour force } & 14.7 & 29.0 & 6.3 & 34.65 \\
\hline & $10.55-18.79$ & 23.89-34.09 & $3.51-9.17$ & $29.51-39.59$ \\
\hline Receiving income & 13.9 & 25.7 & 8.0 & 34.3 \\
\hline support: total & $11.51-16.64$ & $22.04-29.28$ & $5.74-10.22$ & $30.77-37.74$ \\
\hline
\end{tabular}


Table 3. Logistic regression results reporting simple and adjusted odds ratios and 95\% confidence intervals for the associations between income support status and 12-month mental disorders

\begin{tabular}{|c|c|c|c|c|}
\hline & \multicolumn{2}{|r|}{ Simple } & \multicolumn{2}{|c|}{ Adjusted* } \\
\hline & OR & $95 \% \mathrm{Cl}$ & OR & $95 \% \mathrm{Cl}$ \\
\hline No income support (ref) & - & & - & \\
\hline \multicolumn{5}{|l|}{ Any affective disorder } \\
\hline Unemployed & 2.99 & $1.69-5.27$ & 2.79 & $1.59-4.9$ \\
\hline Students & 1.71 & $0.58-5.06$ & 1.56 & $0.53-4.56$ \\
\hline Partnered parents & 3.63 & $1.28-10.31$ & 3.30 & $1.09-9.96$ \\
\hline Lone parents & 2.11 & $1.43-3.12$ & 1.88 & $1.24-2.86$ \\
\hline $\begin{array}{l}\text { Not in the labour } \\
\text { force }\end{array}$ & 2.83 & $1.97-4.07$ & 3.10 & $2.01-4.79$ \\
\hline \multicolumn{5}{|l|}{ Any anxiety disorder } \\
\hline Unemployed & 1.61 & $0.98-2.66$ & 1.41 & $0.86-2.32$ \\
\hline Students & 0.96 & $0.45-2.06$ & 0.82 & 0.391 .73 \\
\hline Partnered parents & 2.18 & $1.08-4.39$ & 1.62 & 0.823 .21 \\
\hline Lone parents & 2.45 & $1.37-4.37$ & 1.81 & $1.02-3.21$ \\
\hline $\begin{array}{l}\text { Not in the labour } \\
\text { force }\end{array}$ & 2.48 & $1.9-3.24$ & 2.33 & $1.69-3.21$ \\
\hline \multicolumn{5}{|l|}{$\begin{array}{l}\text { Any substance use } \\
\text { disorder }\end{array}$} \\
\hline Unemployed & 2.09 & $1.09-4.02$ & 1.77 & $0.84-3.72$ \\
\hline Students & 2.88 & $1.15-7.2$ & 1.79 & $0.73-4.36$ \\
\hline Partnered parents & - & & - & \\
\hline Lone parents & 1.86 & $0.78-4.42$ & 2.54 & $0.99-6.53$ \\
\hline Not in the labour force & 1.21 & $0.72-2.05$ & 2.02 & $1.09-3.75$ \\
\hline \multicolumn{5}{|l|}{ Any mental disorder } \\
\hline Unemployed & 1.86 & $1.18-2.91$ & 1.60 & $1.02-2.54$ \\
\hline Students & 1.71 & $0.89-3.29$ & 1.31 & $0.70-2.47$ \\
\hline Partnered parents & 2.62 & $1.19-5.76$ & 2.11 & $0.99-5.05$ \\
\hline Lone parents & 2.46 & $1.46-4.14$ & 2.02 & $1.21-3.36$ \\
\hline Not in the labour force & 2.16 & $1.71-2.72$ & 2.33 & $1.77-3.06$ \\
\hline
\end{tabular}

Partnered Parents, Lone Parents), these results are more similar to the 1997 results (see Figure 2). A number of post-hoc analyses of the 2007 data were conducted to examine the effect of these different definitions. The first analysis contrasted the prevalence of any mental disorder among the larger group of partnered parents receiving government payments with the subgroup we considered recipients of a partnered parent income support payment. The smaller partnered parent income support group had a significantly elevated prevalence of mental disorders ( $40.4 \%$ versus $20.4 \%$; OR $2.64,1.07-6.51$ ). Analysis restricted to the group identified as lone parent income support recipients compared those who reported income support payments as their main source of income and those who received payment but had an alternative main source of income. Those who were reliant on income support payments for the majority of their income had greater rates of mental disorders than those who were not ( $45.3 \%$ versus $27.6 \%$ ), though this difference was not statistically significant $(\mathrm{OR}=2.17,95 \% \mathrm{CI} 0.84-5.61)$.

Finally, similar comparison of those in the NILF group who reported income support payments as their main source of income and those who did not showed the same pattern of results (33.4\% versus $20 \%$ ), though again this difference did not reach statistical significance $(\mathrm{OR}=2.20$, 95\%CI 0.55-8.86).

\section{Discussion}

The aim of the current study was to use data from the 2007 NSMHWB to examine the prevalence of common mental disorders among recipients of income support payments. We found that mental disorders were more prevalent among income support recipients than nonrecipients, with just over one third $(34.3 \%)$ of income support recipients identified with a 12-month affective, anxiety and/or substance use disorder compared to around $20 \%$ of working age non-recipients. Those receiving income support payments were at particular risk of experiencing affective and anxiety disorders (ORs $>2$ ). Analysis of five major categories of income support recipients (unemployed; students; partnered parents; lone parents; and those not in the labour force/disability support pensioners), found that the prevalence of mental disorders was generally elevated, with ORs from 1.7 to 2.6 compared to non-recipients. However, the profile of disorders differed across payment categories. Those identified as receiving unemployment payments were more likely to experience affective and substance use disorders, partnered parent recipients had markedly elevated rates of affective disorders ( $\mathrm{OR}>3$ ), while lone parent and those not in the labour force/disability payment recipients showed elevated prevalence of all types of disorders. The increased risk of mental disorder for students receiving income support was largely explained by their age. Among respondents with a mental disorder, those receiving unemployment, NILF/disability and, to a lesser extent, lone parent payments were identified with more severe impairment than non-recipients.

The findings are not unexpected, given the well-established relationship between mental health and socioeconomic disadvantage and factors such as unemployment, poverty, and lone parent status [35-39]. Given Australia's non-contributory universal welfare system, with tight income/assets tests on eligibility, receipt of income support is a strong marker of disadvantage. In contrast, while non-recipients are a heterogeneous group, their lack of eligibility for payment indicates that, generally, they have access (either themselves or through other family/household members) to higher level of income and/ or assets. The current analysis also showed that mental disorders were not limited to those individuals receiving disability payments but, rather, were found across all payment types. In fact, the results showed that the majority of income support recipients with mental disorders were receiving payments other than disability payments. 


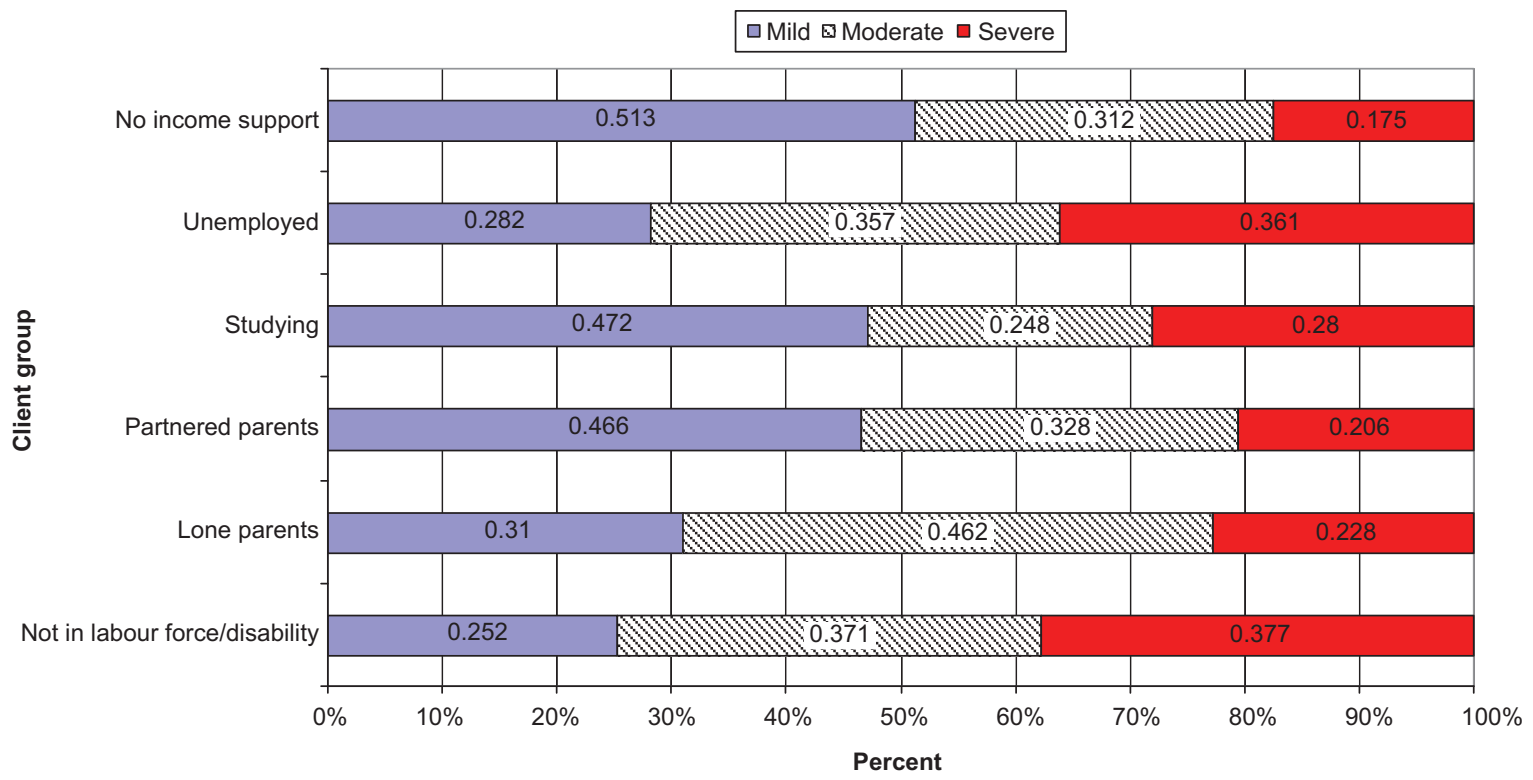

Figure 1. Severity of impairment (mild, moderate and severe) of 2007 survey respondents with 12-month mental disorders, by income support client group and non-recipients.

This is consistent with the ubiquitous nature of mental illness in the community and highlights the fact that mental health needs to be the concern of mainstream as well as specialist policy and services.
The common mental disorders are associated with significant functional impairment, which can impact on a person's ability to undertake productive economic and social roles $[40,41]$. We found that those respondents in

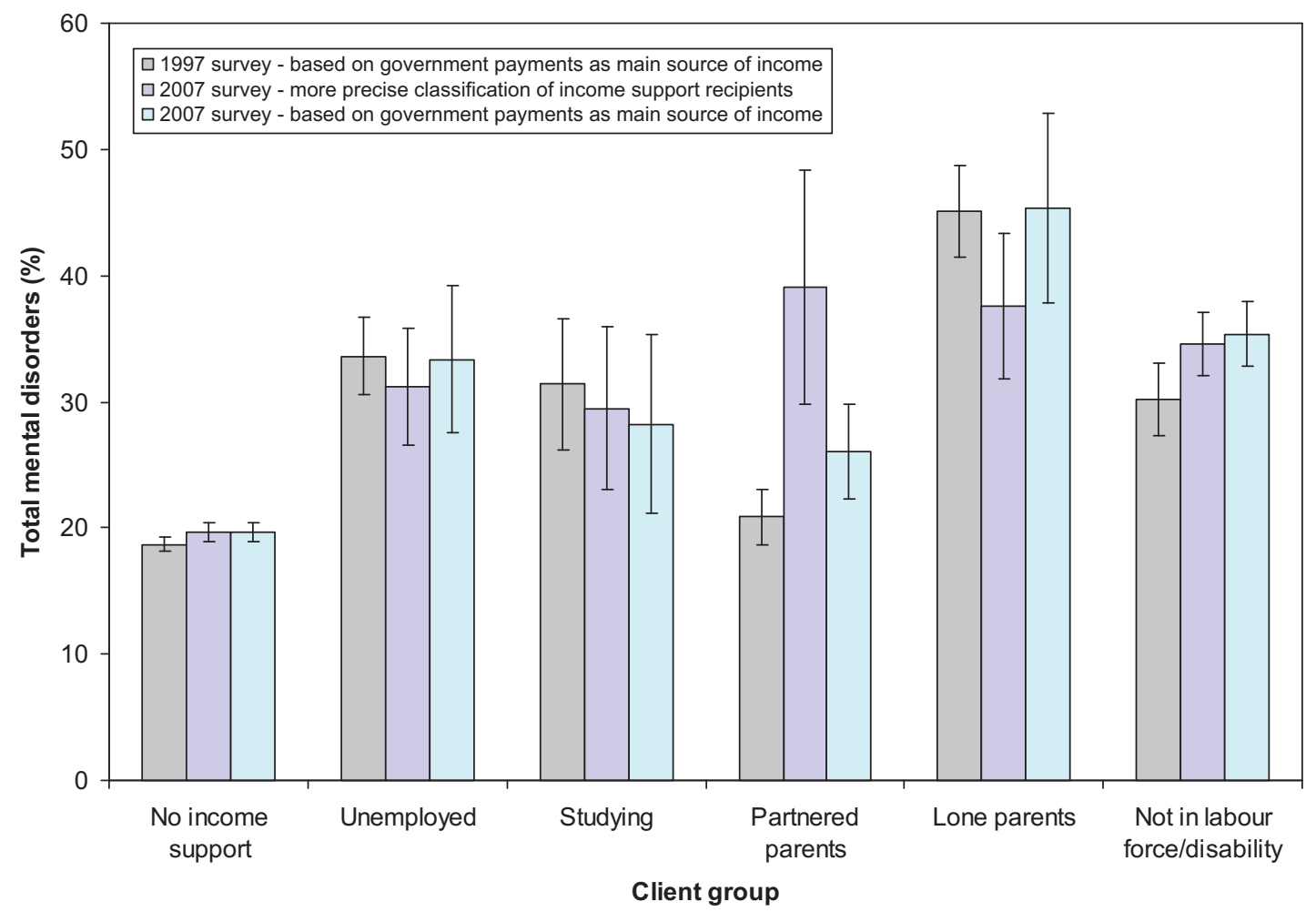

Figure 2. 12-month prevalence of any mental disorder (and standard errors) by income support recipient category: 1997 and 2007. 
the unemployment and NILF/disability groups with mental disorders were much more likely to have severe impairment than those in other income support client groups or the non-recipient population (with over double the prevalence of non-recipients). Although limited by the cross-sectional nature of the data, these findings do provide further support for the interpretation that mental disorders are a barrier to labour-force participation, particularly for these groups, and a potentially important driver of reliance on income support payments. Such an interpretation is also consistent with evidence that income support recipients with other main sources of income (partnered parents, lone parents, and NILF/disability payment recipients) had lower rates of mental disorders than those who reported income support payments as their main source of income. Given the elevated prevalence of mental disorders among working age income support recipients and the focus of a range of social policy on promoting employment, social engagement and social inclusion, the current evidence suggests that a greater consideration of mental disorders in the design and delivery of mainstream welfare and employment services could facilitate the achievement of such policy goals $[2,42]$.

The current findings were largely consistent with the previous analysis of 1997 data [9-11]. As described in the introduction, there have been considerable policy, service delivery and broader environmental changes during the 10 years between surveys. There were competing hypotheses about the possible nature and direction of changes in the mental health of income support recipients. The reforms to mental health services may have facilitated more equitable access to care and treatment, and thereby reduced the relative morbidity of those receiving income support payments. The welfare reforms introduced to increase employment and social participation [22], the increased awareness of mental illness by those involved in delivering services to income support recipients [12], and/ or the greater dissemination of information on effective employment strategies for people with mental illness [43] could also have improved the effectiveness of welfare and employment interventions and led to an improvement in the circumstances of income support recipients. However, in times of high employment and reducing rates of welfare receipt, it may have been those individuals who were most disadvantaged and had the greatest personal barriers (including mental disorders) who were least likely to benefit from the improved economic circumstances. Accordingly, mental disorders may have grown as a proportion of income support population [44-47]. Direct comparison of the 1997 and 2007 results found a slight increase in prevalence from $30.8 \%$ to $34.3 \%$ suggesting that there may now be more disadvantage in the income support population. However, we need to recognize the differences between surveys (see discussion below for details) and the non-significant results which indicate there has not been a reliable change in the prevalence of mental disorders among income support recipients over this period.

The comparative analysis did show a substantial increase in the prevalence of mental disorders among partnered parent recipients, with almost double the prevalence in 2007 compared with 1997. We do not think this reflects a real change but, rather, is a consequence of changes in how this group was defined. With the 2007 survey data we were able to use more detailed information on socio-economic circumstances (e.g. household income) to limit the classification to those partnered parents receiving government pensions and payments who resided in low income households. Many parents, including those with no other source of personal income but with an employed spouse, receive supplementary payments such as family tax benefit but are ineligible for income support payments on the basis of their family income. These respondents were not able to be excluded from the 1997 categorization and, hence, the 1997 classification substantially overestimated the number of partnered payment income support recipients, many of whom were in a better socioeconomic situation than 'true' income support recipients. This was acknowledged as a major limitation in the previous analysis [9]. Although the 2007 analysis also overestimated the size of the partnered parenting recipient population, the inclusion of household income (which could be used to roughly approximate the type of income test applied to income support eligibility) resulted in a much more accurate estimate. Whereas we overestimated the number of partnered parenting recipients by $15 \%$ using the 2007 data, the estimate derived from the 1997 data was more than double the true population size. The more accurate operationalization of partnered parent recipients obviously identified a more socioeconomically disadvantaged group of parents. The current findings are particularly important as they indicate high levels of psychiatric morbidity among partnered parent recipients and this implies that this group should also be a major focus of mental health policy and intervention.

The lone parent recipient group showed a (non-significant) reduction in the prevalence of mental disorders (from $45 \%$ to $38 \%$ ) across surveys. Again, the post-hoc analysis indicated this difference was also likely to reflect the different operationalization of this group in 2007. Unlike 1997, the 2007 categorization included recipients who received government payments but reported another main source of income. Lone parent recipients have high rates of (part-time) employment [17], and the current results may indicate that lone parents who work had better mental 
health than those who did not. It is unclear, however, due to the cross-sectional nature of the data whether this reflects the benefits of work or whether those lone parent recipients with better mental health initially were those more able to work. There is mixed evidence in the literature about the mental health benefits of employment for lone mothers [48-50]. Despite differing from the 1997 figures, the prevalence of mental disorders among lone parent recipients remains almost double the prevalence of non-recipients, and therefore supports a continued focus on the mental health of this group. The striking difference between studies was finding the prevalence of mental disorders was similar for partnered and lone parent recipients. Finally, there was a slight, though non-significant, increase in the prevalence of mental disorders among NILF recipients (largely reflecting those receiving disability support pension (DSP)). This has occurred in the context of increasing absolute numbers of DSP recipients at a time when eligibility criteria have been tightened [17] and when the methodological differences between surveys has decreased our 2007 prevalence estimates in the lone parent and unemployed income support categories. Therefore, this difference may be more meaningful and warrants further investigation. It could be, for example, that an unintended consequence of the expansion of activity and compliance requirements in other payments has been to provide incentives for those with common mental disorders to test their eligibility for the DSP.

This study has a number of limitations that should be acknowledged. Firstly, as information on the actual income support payment received by respondents was not available on the dataset, we had to estimate the main categories of payments from socio-demographic data. While the result of comparison of administrative and survey estimates was reassuring, this process was obviously not entirely accurate. In particular, our inability to differentiate recipients of disability support pension from other payments for those not participating in the labour force does limit conclusions drawn about this important segment of the income support population. The analysis was restricted to the working age population. Further research contrasting age pension recipients and those with independent means in retirement is also warranted, particularly given the focus on Australia's ageing population and recent changes to superannuation and retirement policy. The response rate to the 2007 survey was $60 \%$, which was considerably lower that the 1997 response rate of $78 \%$. While the results may be subject to potential bias, the correspondence between the estimates of subpopulations and administrative data does somewhat allay these concerns. In addition, we report analysis of cross-sectional data and therefore cannot interpret the association between income support receipt and mental disorders causally. The comparison between the 1997 and 2007 results was restricted by changes in methodologies and instruments used. Finally, the 2007 survey was conducted prior to the full impact of the global financial crisis. Thus, while the data reflect most contemporary national information on mental health in Australia, the changed economic circumstances post-survey may have altered the profile and the socio-demographic correlates of mental disorders in Australia.

Despite these limitations, this analysis makes an important contribution to updating our knowledge of mental disorders among income support recipients in Australia. It confirms that mental disorders are highly prevalent among income support recipients (experienced by just over one third of recipients each year). With better data in 2007 we found that partnered and lone parent income support recipients reported similar levels of mental disorders. We also found that those recipients reliant on income support as their main source of income had poorer mental health than those with other income sources, a finding with potentially important policy implications. The findings suggest that policy and service delivery that better targets and provides appropriate support to the large number of income support recipients with mental disorders may facilitate the achievement of policy goals.

\section{Acknowledgements}

The authors thank Bill Buckingham for comments on an earlier draft of this paper.

Declaration of interest: The 2007 NSMHWB was funded by the Australian Government Department of Health and Ageing, and conducted by the Australian Bureau of Statistics. Peter Butterworth was supported by the National Health and Medical Research Council Career Development Award Fellowship 366781. The authors alone are responsible for the content and writing of the paper.

\section{References}

1. Goldman HH, Glied SA. Mental health in the mainstream of public policy: research issues and opportunities. Am J Psychiatry 2008; 165:1099-1101.

2. WHO. The world health report 2001: mental health new understanding, new hope. Geneva: World Health Organization, 2001.

3. Mental Health Standing Committee of the Australian Health Ministers' Advisory Council. Council of Australian Governments national action plan for mental health 2006-2011: progress report 2006-07. Canberra: COAG, 2008.

4. Mathers C, Vos T, Stevenson C. The burden of disease and injury in Australia - summary report. Canberra: Australian Institute of Health and Welfare, 1999.

5. Begg SJ, Vos T, Barker B, Stanley L, Lopez AD. Burden of disease and injury in Australia in the new millennium: measuring health loss from diseases, injuries and risk factors. Med J Aust 2008; 188:36-40. 
6. Danziger SK, Corcoran M, Danziger S et al. Barriers to the employment of welfare recipients. In: Cherry R and Rodgers W.M. III, eds. Prosperity for all? The economic boom and African Americans. Ann Arbor: Russell Sage Foundation, 2000.

7. Kessler RC, Frank RG. The impact of psychiatric disorders on work loss days. Psychol Med 1997; 27:861-873.

8. Sanderson K, Andrews G. Common mental disorders in the workforce: recent findings from descriptive and social epidemiology. Can J Psychiatry 2006; 51:63-75.

9. Butterworth P. Estimating the prevalence of mental disorders among income support recipients: Approach, validity and findings. Canberra: Department of Family and Community Services, 2003.

10. Butterworth $P$. The prevalence of mental disorders among income support recipients: an important issue for welfare reform. Aust $N$ Z J Public Health 2003; 27:441-448.

11. Butterworth P, Fairweather AK, Anstey KJ, Windsor TD. Hopelessness, demoralization and suicidal behaviour: the backdrop to welfare reform in Australia. Aust N Z J Psychiatry 2006; 40:648-656.

12. Butterworth P, Berry H. Addressing mental health problems as a strategy to promote employment: an overview of interventions and approaches. Australian Social Policy 2004:19-50.

13. Department of Family and Community Services. Inquiry into poverty and financial hardship. Occasional Paper No. 9. Canberra: Department of Family and Community Services, 2008.

14. Burgess PM, Pirkis JE, Slade TN, Johnston AK, Meadows GN, Gunn JM. Service use for mental health problems: findings from the 2007 National Survey of Mental Health and Wellbeing. Aust N Z J Psychiatry 2009; 43:615-623.

15. Whiteford H, Groves A. Policy implications of the 2007 Australian National Survey of Mental Health and Wellbeing. Aust $N Z J$ Psychiatry 2009; 43:644-651.

16. Brown J. What's next for Welfare-to-Work? Issues Analysis. Sydney: Centre for Independent Studies, 2009.

17. Harmer J. Pension review background paper. Canberra: Department of Families, Housing, Community Services and Indigenous Affairs, 2008.

18. McClure P. Participation support for a more equitable society: final report of the Reference Group on Welfare Reform. Canberra: Commonwealth of Australia, 2000.

19. Martin JP. What works among active labour market policies: evidence from OECD countries' experiences. Paris: Organization for Economic Co-operation and Development, 1998.

20. Saunders P. Issues in Australian welfare reform. In: Saunders P, ed. Reforming the Australian welfare state. Melbourne: Australian Institute of Family Studies (AIFS), 2000;1-43.

21. Saunders P. Mutual obligation, participation and popularity: social security reform in Australia. J Soc Policy 2002; 31:21-38.

22. Commonwealth of Australia. 200506 budget overview: welfare to work. Canberra: Commonwealth of Australia, 2005.

23. Australian Bureau of Statistics. Australian social trends, data cube. Canberra: Australian Bureau of Statistics, 2008.

24. Slade TN, Johnston A, Oakley Browne MA, Andrews G, Whiteford H. 2007 National Survey of Mental Health and Wellbeing: methods and key findings. Aust N Z J Psychiatry 2009; 43:594-605.

25. Australian Bureau of Statistics. 2007 National Survey of Mental Health and Wellbeing: users' guide. Canberra: Australian Bureau of Statistics, 2009.

26. Andrews G, Hall W, Teesson M, Henderson S. The mental health of Australians. Canberra: Mental Health Branch, Commonwealth Department of Health and Aged Care, 1999.

27. Henderson S, Andrews G, Hall W. Australia's mental health: an overview of the General Population Survey. Aust N Z J Psychiatry 2000; 34:197-205.
28. Kessler RC, Ustun B. The World Mental Health (WMH) survey initiative version of the World Health Organization (WHO) Composite International Diagnostic Interview (CIDI). Int $J$ Methods Psychiatr Res 2004; 13:93-121.

29. World Health Organization. International statistical classification of diseases and related health problems (10th revision). Geneva: World Health Organization, 1992.

30. Department of Families, Housing, Community Services and Indigenous Affairs. Income support customers: a statistical overview 2005. Canberra: Commonwealth of Australia, 2009.

31. Harmer J. Pension review report. Canberra: Department of Families, Housing, Community Services and Indigenous Affairs, 2009.

32. Daniels D. Trends in the receipt of income support by workforce age people 1978 to 2007. Canberra: Parliament of Australia, 2008.

33. Lee S, Davis WW, Nguyen HA, McNeel TS, Brick JM, FloresCervantes I. Examining trends and averages using combined cross-sectional survey data from multiple years. Los Angeles: UCLA Center for Health Policy Research, 2007.

34. Rizzo L, Moser RP, Waldron W, Wang Z, Davis WW. Analytic methods to examine changes across years using HINTS 2003 and 2005 data. Bethesda, MD National Cancer Institute, 2008.

35. Dohrenwend BP, Levav I, Shrout PE et al. Socioeconomic-status and psychiatric disorders: the causation-selection issue. Science 1992; 255:946-952.

36. Kessler RC, House J, Turner J. Unemployment and health in a community sample. J Health Soc Behav 1987; 28:51-59.

37. Brown GW, Moran PM. Single mothers, poverty and depression. Psychol Med 1997; 27:21-33.

38. Butterworth P, Rodgers B, Windsor TD. Financial hardship, socioeconomic position and depression: results from the PATH Through Life Survey. Soc Sci Med 2009; 69:229-237.

39. Fryers T, Melzer D, Jenkins R. Social inequalities and the common mental disorders: a systematic review of the evidence. Soc Psychiatry Psychiatr Epidemiol 2003; 38:229-237.

40. Kessler RC, Heeringa S, Lakoma MD et al. Individual and societal effects of mental disorders on earnings in the United States: results from the National Comorbidity Survey Replication. Am $J$ Psychiatry 2008: 165:703-711.

41. Kessler RC, Walters MS, Forthofer MS. The social consequences of psychiatric disorders III: probability of marital stability $\mathrm{Am} \mathrm{J}$ Psychiatry 1998; 155:1092-1096.

42. Social Exclusion Unit. Mental health and social exclusion. London: Office of the Deputry Prime Minister, 2004.

43. Bond GR, Becker DR, Drake RE et al. Implementing supported employment as an evidence-based practice. Psychiatr Serv 2001; 52:313-322.

44. Moffitt R, Cherlin A. Disadvantage among families remaining on welfare. Baltimore: Johns Hopkins University, 2002.

45. Zedlewski SR, Alderson D. Do families on welfare in the postTANF era differ from their pre-TANF counterparts? Washington DC: Urban Institute, 2001.

46. Moffitt R, Cherlin A, Burton L, King M, Roff J. The characteristics of families remaining on welfare. Baltimore: John Hopkins University, 2002.

47. Loprest PJ, Zedlewski SR. Current and former welfare recipients: how do they differ? Washington DC: Urban Institute, 1999.

48. Macran S, Clarke L, Joshi H. Women's health: dimensions and differentials. Soc Sci Med 1996; 42:1203-1216.

49. Baker D, North K. Does employment improve the health of lone mothers? Soc Sci Med 1999; 49:121-131.

50. Zabkiewicz D. The mental health benefits of work: do they apply to poor single mothers? Soc Psychiatry Psychiatr Epidemiol 2010; 45:77-87. 